\title{
Management Controls and the Gendering of the Workplace: The Case of eHealth Projects in Sweden
}

\author{
Gunilla Myreteg \\ Uppsala University
}

The article provides knowledge about gender practices at the workplace, and the inequalities between sexes, when the involvement of women increases in three IT based implementation projects (eHealth services for Swedish citizens). Interview data about participants' activities and roles in relation to management controls (direct, indirect, and internalized controls) were interpreted through content analysis. Findings illustrate unclear and implicit management controls. Women project members generally contributed with internal healthcare expertise. Despite a big number of participating women, the feminine identity, gendered practices and power relations were reproduced. To reduce gender inequalities, management controls need to support the agency of women.

Keywords: Gender Inequality, Gender Practices, Gender Workpalce, IT implementation, Management Control

\section{INTRODUCTION}

The starting point for this research is that there are inequalities in society and in work life. Acker defines organizational inequality as "systematic disparities between participants in power and control over goals, resources, and outcomes; workplace decisions such as how to organize work; opportunities for promotion and interesting work; security in employment and benefits; pay and other monetary rewards; respect; and pleasures in work and work relations." (Acker, 2006, p.443) To some extent, inequalities are built into the capitalist model (with the distribution of power between the owner, manager, and the worker), but they further derive from gender, and also from class and race. They occur for example as differences in opportunities (for example what role or job one can take on) or in rewards (such as level of salary). Generally, inequalities arise when we believe that there are the "others" or "them", as separated from "us": people tend to make the distinction between in-group and out-group members (cf. Duszak, 2002). The division of members of a workplace into the two groups of "men" and "women" is considered one of the main obstacles in attempts to advance equality, because it makes people assume that there are fundamental dissimilarities between men and women (Brunila \& Ylöstalo, 2015).

In the workplace, both men and women perform gender in a process where social structures are (re-) produced (Acker, 1990; Carmona \& Ezzamel, 2016). Inequalities are thus founded on institutions (such as structures and rules supported by management control systems), interactions between people (as prescribed within different work roles), and identities that are shaped and developed in practice and that are context specific (cf. Nentwich \& Kelan, 2014). The present article takes as a starting point the wish to question inequalities in organizations, so that in the future, people can tear them down. In order to do that, we need to know more about the (re-)production of (expectations regarding) the behaviors of men and women-the gendering of the workplace-as a dynamic process (Carmona \& Ezzamel, 2016). 
Today, we see an increasing number of women taking an interest in IT systems and IT based implementation projects. One example is the development of eHealth that is current on a global scale. A very interesting question is what happens in the workplace, especially regarding issues connected to involvement, roles, and relationships between employees, when there are increasing numbers of women working in IT based projects. We need to know more about the experiences and practical situations of, and the ideas about, women that participate in such projects.

In other contexts, research has highlighted how the same activities were described differently depending on whether men or women performed the acts (Nentwich \& Kelan, 2014). An example was how at a burger restaurant, women were regarded to be better equipped than men at meeting rude customers and to remain pleasant, while at an insurance company, the same behavior was considered to be "manly", because it requires strong self-control (Leidner, 1991). Another example of the gendering of the workplace is how an employee, in order to do the job "properly", deliberately acts in a manner that is in accordance to expectations in relation to being a man or a woman ("gender identity"; Nentwich \& Kelan, 2014). The present research investigates the gendering of the workplace, (re-)produced by project groups that implement eHealth systems for citizens.

In research, there are different means to try to avoid or dismantle issues of inequality between men and women: based on individual, biological, or structural explanations. Individual explanations put forward the importance of the choices and willingness of the individual him- or herself, often proposing that women does not aspire leadership positions but that training courses can help women to take on leadership roles (see for example Hernandez Bark et al., 2016). In biological studies, the implications of for example different levels of testosterone was investigated (see for example McCarthy et al., 2015). The present article however rejects the individualized explanation (hereby supporting Rottenberg, 2014) and searches for answers beyond the biological explanation of inequalities between the sexes. This article is a feminist study that regards social structures as the most important explanation to inequalities between the sexes. The gendering of the workplace and the (re-)production of gender is studied in a setting of social structures, including the organizational structure and with a special focus on management controls.

Archer (2006) argues there are mechanisms within organizations that keep status quo intact. One such mechanism is the set of management controls that employees draw upon to perform tasks and duties. Many women are currently involved in IT based implementation projects regarding eHealth systems. We know little about how activities and roles are (re-)produced and explained as gendered practice in this setting-and how organizational controls are involved. The aim is foremost exploratory. The study is qualitative in its approach and strives to identify and interpret the gendering processes in the implementation projects.

\section{MANAGEMENT CONTROLS AND GENDERING}

\section{Gender Studies: Issues of Inequality}

The literature in gender studies is difficult to synthesize. The present article regards gender as a routine accomplishment (cf. West \& Zimmerman, 1987). Nentwich and Kelan (2014) did a literature review that resulted in a framework of five themes of gender research. The present research is, by that framework, making use of structures and hierarchies as explanatory dimensions. Actors are embedded in structures that shape their possibilities in life, but at the same time, the actors are actively involved in processes that (re-)produce and resist structures (Giddens, 1984). Since the individual is an autonomous actor with agency, there is always the possibility to act independently and to make a free choice. Thus, actors may reproduce stereotyped expectations or identities, or choose to act differently (cf. Nentwich \& Kelan, 2014). History and precedence tend to legitimize inequalities, but changes are possible, even though they may be difficult to achieve (Mohanty, 2003).

Work in the workplace may in fact be organized in a manner that sustain inequality ("inequality regimes"; Acker, 2006) by how the general requirements are set up, how the hierarchies of different jobs are arranged relative one another, how people are recruited, how wages are set, and by how informal interactions are carried out during daily work. The use of inequality regimes assures that processes and 
practices are fixed. They thus maintain the current inequalities, which may be bigger or smaller in different organizations (Acker, 2006). However, inequality regimes may be more or less formalized in the organization. Gherardi and Poggio (2001) identify rules and tactics that apply to the workplace when women enter a masculine domain. These consist of different manners or ambitions that is available to women, in order to be accepted by men. First, there are the rules that apply for everyone, regardless of sex ("necessary conditions"). Next, there are rules that work as a recipe for women to be accepted through masculinization (to create a womanhood that resembles the male ideal type). Finally, there are a third group of rules, which Gherardi and Poggio describes as the tactics enacted by women, through their attitudes and behaviors, to "mark out and defend their space within organizations" (Gherardi \& Poggio, 2001, p.254) by emphasizing their difference from men, and thereby to put men at ease.

In organizations, there are also a set of more formalized controls, used by managers to ensure that the employees work with the aim to realize the goals of the organization (Flamholtz et al., 1985). Acker (2006) points out three types of organizational control: direct controls (rules, punishment, rewards, coercion, and violence), indirect controls (control through technology, information, recruitment), and internalized, often "invisible", controls (beliefs, values, pleasure, fear, self-interest; economic, status, and identity interests). She concludes that actors with a powerful position have the possibility to control others, and themselves, with the self-interest of preserving their position (Acker, 2006, p.455). Institutions and structures, manifested in organizational controls, become taken-for-granted truths that are invisible to actors, and by this, they restrict agency (Giddens, 1984). This article explores how the formalized organizational controls are involved in the (re-)production of activities and roles as gendered organizational practices.

\section{Women in a Technological Workplace}

There is a debate over the strengths and limitations of equal employment opportunity policies within the broad industries of technology, to which Wajcman (2010) relates. She finds that these industries are marked by cultures of masculinity and stereotyping, due to the prevailing gender structures, such as the "geek culture" that is prominent within computer science (Wajcman, 2010, p.145). She argues that women therefore are required to masculinize their gender identity, which can make young women select other careers or make older women leave the industry. What is regarded as "feminine" and "masculine" is however not constant, but in flux and open to reinterpretation-as any set of practices (Brunila \& Ylöstalo, 2015; Giddens, 1984).

Previous research has empirically shown that gendered practices and assumptions are embedded in the processes of organizations (for a compilation, see for example Selberg, 2012). The "doing gender" is foremost claimed to be done unintentionally (Zimmerman \& West, 1987), but Martin (2006) has later illustrated that people also practice gender intentionally. The repertoire of actions or behavior that is socially and culturally available for "doing gender" are stereotypically associated with either of the sexes (Martin, 2006). The repertoire of gendering practices includes accepted dress codes, demeanor, language, expressions, actions and interests (Martin, 2006; Zimmerman \& West, 1987). Hines (1992, p.327) forwards the notion of the "universal feminine" and the "universal masculine", based on the metaphor of yin and yang, where femininity is linked to, for example, caring, experience, stillness, emotions, and the tacit-while masculinity is connected to providing, reason, action, to be objective, and the explicit. This understanding of what represents the "masculine" is closely aligned with the ideas of Wajcman (2010) and what she refers to as the "masculine culture" of the technological workplace.

Wajcman (2010) also synthesized the feminist theories of technology, by conceptualizing the link between gender and technology. She argues that gender and technology are mutually shaping each other in contextually situated processes; technology is both a source and an outcome of fluid gender relationships. This is noteworthy in the light of other research that suggests that men and women have a tendency to take on different, gendered, positions toward technology (Kelan, 2007). In that study, men generally described technology as a toy while women described it as a tool. While we cannot know what difference it would do to have women more active in the design phase, Wajcman (2010) argues that it is important that women have the equal economic and social circumstances as men, in order to support the 
capacity of women within the sociotechnical configurations, and to avoid their exclusion. This is further supported by the argument that it is important to have different voices, and multiple values, heard in organizations and society when we "present a particular point of view, or argue a case" (Broadbent, 1998, p.274). The present research similarly argue that the development and implementation of eHealth systems for citizens need to be a common, shared, process where both men and women are free to participate on equal terms.

\section{METHOD}

The internet service Journalen provides Swedish citizens with their patient accessible electronic health record (PAEHR) through a national patient portal, 1177 (Inera, 2018a). The EHR information is accessible by the national health information exchange platform managed by Inera AB (Inera, 2018b). This national coordination implies that every citizen has the same PAEHR interface, regardless of where in Sweden he or she lives. However, since every county council or region is autonomous, each has decided on what pieces of information should be accessible in that geographical area. Therefore, citizens will find different clinical contents in Journalen depending on where in the country they live and have received healthcare. Examples of contents that are accessible are medical notes from EHRs, lab results, prescribed medications, referrals, and vaccinations (for a more elaborate description, see Moll et al., 2018).

Semi structured interviews were carried out in three county councils in Sweden, each representing a project implementing Journalen and connecting to the national eHealth platform. The county councils are listed (see Table 1) by date of implementation (B was the first out of these three, and D was the last). We interviewed a total number of eight respondents, between September 2017 and September 2018. The respondents are referred to by the use of a key (see Table 1) for confidentiality reasons. Respondents signed an agreement to participate. We reminded each respondent that participation was voluntary: she/he could choose not to answer a particular question or could choose to end the interview at any time, without any consequences.

A team consisting of four (female) researchers developed the interview questions, and two of us carried out the interviews. The interviews were set up through a contact person at each geographical region. We required at least one male and one female respondent that had been active in the implementation project. All interviews were recorded and transcribed.

The analysis was a qualitative, directed, content analysis (cf. Hsieh \& Shannon, 2005). Theoretical concepts and previous research guided the coding of the material. Concepts were sorted by management controls (direct, indirect, and internalized), and doing gender (ongoing activities as stereotyped "male", "female", or as neutral). The interpretation involved comparisons between different respondents' answers in order to understand the (possible) importance of management controls in the construction of gender and the gendering of the workplace. 


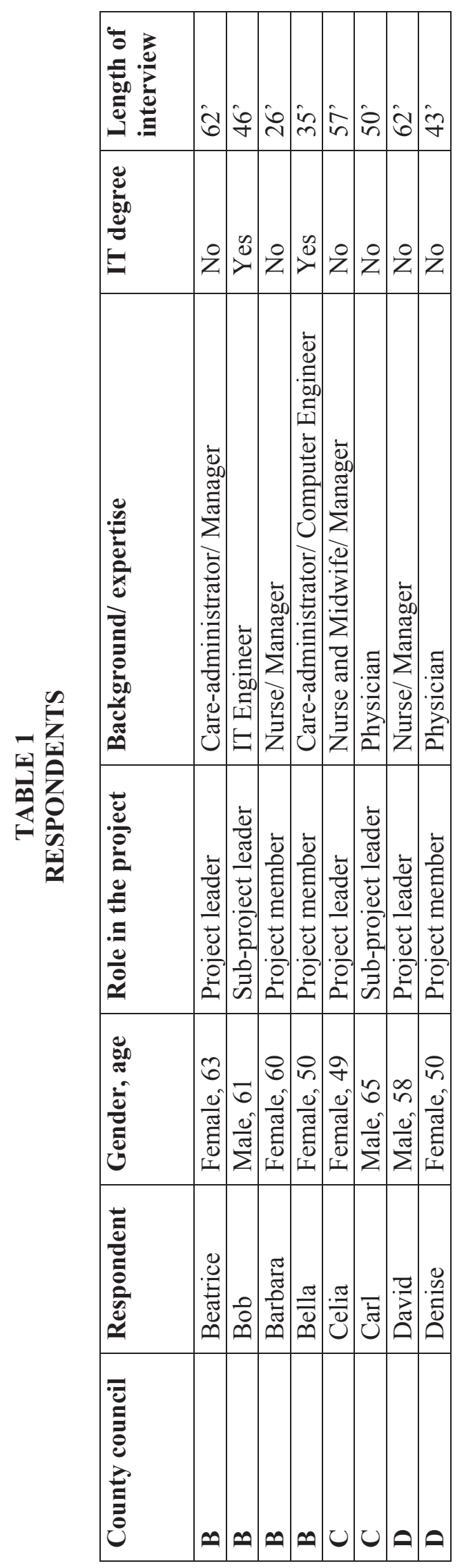

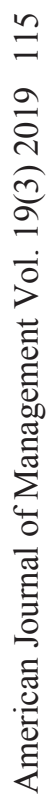




\section{RESULTS AND DISCUSSION}

The county council of Uppsala (today Region Uppsala) was an early starter in the area of eHealth (Scandurra et al., 2013). In Uppsala, the vision was to give the citizens access to "all information"-or at least to as many pieces of information as was technologically possible. However, the process gave rise to negative attitudes, foremost among physicians and their unions (Erlingsdóttir \& Lindholm, 2015). At least one respondent from each of the currently investigated county councils referred to the implementation process in Uppsala. It is clear that this first example of implementation process has gotten much attention and has become somewhat of a benchmark to other county councils/regions. In the present study, there were both positive and negative remarks regarding the implementation process in Uppsala.

\section{Inequalities are Connected to the Healthcare Hierarchy}

Respondents generally agreed that gender is of no importance to their experiences and practices in the workplace. Rather, they considered healthcare hierarchy to be the primary explanation to possible inequalities in the organization. Respondents experienced that in healthcare, men who are in search of challenges can become a manager-but that this path is less open to women. Women, however, can get involved in development projects, possibly in the role of project leader. This illustrates a situation of inequality: women have fewer opportunities than men do in regards of finding a position that is personally rewarding and regarding to take on authoritative positions in the organization. In all investigated regions, there were many women in the projects. Bella says that women now dominates in IT work: "Men disappear from our department. It is not the women who leave, but the men. We don't have any men in our section right now." Thus, in Region B, men even start to withdraw from participation in IT based project work. It is unclear where the men turn to, instead of taking part in the IT work. The women, however, remain.

\section{Few Formalized Project Management Controls}

Organizational controls (direct, indirect, and internalized) are organizational mechanisms that can preserve inequalities in organizations (organizational regimes; Acker, 2006). The analysis identified surprisingly few examples of controls that respondents referred to as being important to their own involvement, activity, role and position in the project. One could expect a highly complex project to be managed with the help of clearly stated controls, related to project objectives (cf. Flamholtz et al., 1985; Liu et al., 2010).

The direct control that respondents mentioned was "to be valuable": "Every quarter, I need to prove that I deliver. Otherwise I'm out." (Bob, external IT expert), "You need to show that you are willing. And that you are able." (Beatrice, project leader). This is an example of what Gherardi and Poggio (2001, p.252) find to be "rules for everyone"; necessary conditions that might be "apparently genderless" since every individual needs to apply them but that may hold different consequences. In the interviews, what was regarded as valuable and value creation was notably vague. Male respondents tended to focus on their actual delivery (what they achieved) while women mentioned their intent or manner (how/that they achieved).

The respondent David furthermore describes that he monitors the IT specialists, to check that they do what is expected of them: "Most of these specialist don't actually understand the context of what they are doing, but maybe that isn't their role, either." In a highly complex project, it may be difficult for management to design clearly defined direct controls. Due to the many different types of actors involved, it was difficult for each actor to have the complete overview and understanding of all the tasks and problems of the process.

Respondents' answers in relation to direct controls thus did not reveal any clearly gendered patterns, but the indirect controls showed a somewhat different result. The most often mentioned indirect control was "recruitment". Men described more self-evident that they were suitable to the challenge. Carl (sub project leader) says the task came "natural" to him, due to his position in the organization and previous experience: "I wanted to do this. It was obvious. No one else desired or had the position to --- and I was 
quite convinced it would go well." Another male example is David, who was challenged by a manager: "He asked me, 'Do you want to, are you able to, do you dare?". On a direct question from the interviewer if he considers this was to "take a risk", he answers: "Yes, but that is fun!"

To contrast, the female project leader, Beatrice, tells her story of a convincing and forceful recruiter:

"I had seen the ad and made a printout; I was thinking about it... Then I got an e-mail from him [her current manager] saying 'I saw you, I have a job for you, why don't you apply for it?' Therefore, I did. I thought, 'If he says so, I will do it.' [Laughing] So I did." Denise (project member) points out the need of stability within the group, and that it is important that you can trust the project leader and his closest co-workers and managers, in order to establish a dialogue: "It was the same people on these positions, the keypositions ... There were no changes in people. We had a, sort of, functioning communication."

The gendered pattern is thus that while men consider themselves powerful players in their own right, women need to be coaxed into the project or consider themselves team players that foremost act together with other people. The analysis recognize this as a stereotyped masculinized role of a competitive and risk-taking individual, as contrasted to a stereotyped feminized role of a collaborative and listening woman, in search of stability (cf. Hines, 1992).

Interestingly, the internalized controls dominated the respondents' narratives. Answers to the question "Why did you want to participate in the project?" reflect this. For example, Celia (project leader) was previously over-worked, due to poor scheduling, and wanted "[t]o escape the bad organization and not have to work evening and night shifts. --- But then I found out that it was really fun, and it was a kick that I learnt something new, and I felt I was good at it too." That IT support, often considered a "geek" and male task, could be an interesting task for her, a woman in healthcare, was surprising to her. Barbara, on the other hand, is a female who describes herself as a "combination" of male and female interests and values: "I'm a bit manly, kind of [laughing]. I am a mix, if you can, generally, be that", and says she is driven by a technological interest, her restlessness, and that she likes a challenge. She explains this a result of being the mother of two boys, and of having four brothers. This reminds of how Gherardi and Poggio (2001) found that a woman engineer had to deny her femininity in order to be accepted at her new workplace. Her status was based on a male type of professionalism, expressing that she "no longer" was a woman, but "an engineer" (Gherardi \& Poggio, 2001, p.251) - resembling of how Barbara describes herself as withdrawing from the female arena by being "a bit manly" and "a mix". At the same time, when the gender expectations are broken, there is need of remedial, ceremonial, work to repair the breakdown (Gherardi \& Poggio, 2001). Barbara feels she has to explain and legitimize that she is not playing her role "to be a woman": because she spends a majority of her personal life with boys (brothers and sons) they have influenced her into this. She thus constructs an image of herself that resembles the male ideal type of an IT "geek", and describes that her behaviors and attitudes resembles what would be expected from a man. This masculinization of womanhood is what Wajcman (2010) argues is typical behavior for women in the technological workplace, and this was also suggested by Gherardi and Poggio (2001) to be a successful recipe for female behavior, in order to be accepted among men.

A more stereotyped feminine role is played by Denise, who says that she has an urge to give voice for those who will use the system, to someone that listens: "The classical situation is that you just sit down -- and complain: but no one cares. Or else, you can pick a channel to bring about [your message]." She describes herself as a mediator between people in power and the future users of the system; her own needs are less important. In the conceptualization of Gherardi and Poggio (2001, p.254), this would be the tactics of deliberately assuming a female position (showing meekness and humility, and not competing with men) in order to secure acceptance and trust at the workplace. 


\section{Cooperative Implementation Strategies to Avoid Conflicts}

All county councils expressed that they wanted to avoid conflicts among stakeholders. Therefore, they applied variations of a cooperative implementation strategy. David says, "The condition was that we, together with the organization, would produce a foundation and suggestion for the implementation. --We could go quite far in making compromises. --- Really, it was about cooperation.", and Denise agrees, "I have to say that this was carried out through dialogue and in consensus. It really was." County council $\mathrm{D}$ thus showed a clear democratic stance for its processes.

In the case of county council $\mathrm{C}$, however, there were signs of a slight discrepancy between what was said and done (cf. Brunsson, 1993):

"I had a very clear strategy. --- The decision to implement was already made, it was not a question of whether to implement it or not. --- We had [three workshops], and it stopped at that. --- What I learnt through the years, is to not give [participants] too many choices." (Carl, sub project leader)

After the second workshop, he and the main project leader, Celia, made a suggestion that they presented to the group as a final solution, not possible to negotiate:

"[We] put together a suggestion: 'This is how it will be'. We had a last meeting where we presented it to the group: 'We know you don't agree, but this will happen, it's our suggestion to the politicians.' So it was very easy, really, compared to our expectations." (Celia)

The realized process was thus not especially democratic, despite the three workshops. In the end, the politicians in this county council made further changes to the suggestion emanating from the project group: "I did not argue against it ... but it was not in accordance to what we, nearly, had agreed upon in the organization." (Carl)

In county council B, the strategy was not explicit, but Beatrice, the project leader, speaks of the problem that doctors do not fully trust people who lack medical training. Therefore, she finds it important to be able to discuss issues with members of the organization, and to make sure that they understand the issues: "I thought they had got it, well, that they were somewhat prepared --- We had to go in reverse. --We had to start all over." (Beatrice) Her stance interprets as a sign of a cooperative effort aimed at avoiding conflict, and that her position as project leader was not quite as powerful as was needed: she could not move the process forward without having everyone onboard. Common to all county councils was the wish to avoid the conflicts, articles in media, etcetera, which had happened to the first region (Region A).

\section{Discussion}

The implementation strategies to avoid conflict, together with the dominance of recruitment as a means to manage the respective project group, create situations where group members want to avoid "making trouble", such as raising any issues regarding inequalities between the sexes (cf. Mohanty, 2003) or breaking the gendered norms without doing remedial work (cf. Gherardi \& Poggio, 2001). We also need to recognize that actors tend to defend status quo (Acker, 2006). Sometimes, people who themselves are unequal and are suppressed by others cannot see this. None of the respondents acknowledged that there were differences in power positions between men and women in the project. David (project leader) however states that men often are overconfident: "We men, we always overestimate our ability, so it is easier for us to change track, as myself: I left child care and attacked IT without really having the competence for it" (also, notice the forceful, masculinized, image of "attack" for entering a new field). This is an individually based, rather than a structurally based, explanation to inequality between the sexes (cf. Rottenberg, 2014). 
Furthermore, that Bella, a woman with IT education, downplays her expertise and ability to grasp the job during several years of work, points to the need of remedial work to recover the break of gendered norms (cf. Gherardi \& Poggio, 2001): "So, really, no one knew what this was about. So I have had to, it has taken some years [laughter] before one gets it." (Bella) The statement is a means to distance herself from the "geek" status connected to IT work (cf. Wajcman, 2010). Despite her formal IT training, she had to "search", and to "wait", for insights rather than to "attack" (cf. David, above) the field. It is important for women, also in this setting, to demonstrate that they are female, "showing meekness and humility" (Gherardi \& Poggio, 2001, p.254), such as waiting for insights (cf. Hines, 1992). It is a valuable strategy for the individual woman to avoid making unnecessary trouble, and to make descriptions of herself that accord with expectations of "female" behavior. The implementation strategy in combination with the current management controls reproduced gender inequalities and kept back any individual female opposition.

\section{CONCLUSION}

The study supports previous research (Gherardi \& Poggio, 2001) that argues that women who take on a role that is not in line with gendered expectations, or that break the rules that define "proper" behavior by women (and thus challenge gender norms and values), also need to take actions in order to repair the broken down order (ceremonial, remedial work). Otherwise, other organizational members (Gherardi \& Poggio, 2001) might not accept them. Change efforts (the "negative" project of tearing down inequalities) need to be combined with the "positive" project of creating equality (the building and construction of equality; Mohanty, 2003). It is thus not surprising to find that actors, also in this setting, were reluctant to point out any inequalities between the sexes. The result was an overall reproduction of stereotyped expectations and roles (the doing gender), rather than a breakdown of stereotypes.

This situation is parallel to how Acker (2006) states that we reconfigure segregation rather than reduce it. It is true that many women are involved in eHealth projects. This could be a reduction of inequalities; however, most women in this context maintain their position of being "health care experts that know nothing about IT". The role and position of a woman is still defined in comparison to the man (cf. Gherardi \& Poggio, 2001). Women are allowed into IT projects. This could be a reduction of inequalities; however, the inequalities between men and women are maintained: men become managers and women who want a challenge has to look for another path. Men allow women to get involved in IT projects: by persuasion and coaxing if necessary. There are also some signs that men already are leaving this area, to get involved in other tasks, and are "disappearing"-while women remain. The division between what is considered typically male and female roles or tasks are largely reproduced, and men sustain the privileged position.

Management controls also play a part in the setting of boundaries for agency and for doing gender, for men and women, in implementation projects regarding eHealth systems for citizens. This insight enriches previous ideas (Carmona \& Ezzamel, 2016) regarding the gendering of the workplace. Actors need to show that they create value (direct control: following the norms), they are recruited based on previous behavior (indirect control: following expectations), and they are driven by interests to achieve a high quality eHealth system for citizens (internal controls: making use of their previous experiences and expertise). Management controls, however, did not stimulate actors to try new behavior, to challenge current norms, or to question status quo. In a setting where actors are intent to avoid conflicts among the project stakeholders, individual project members' agency will be similarly restricted.

A practical implication is that the number of participating women is not a sole remedy against inequalities between the sexes. Gendered practices and power relations were, in the current study, reproduced despite female participants, and even female project leaders. We can compare this to what Pilgeram (2007) found in a study of livestock auctions in the USA: there an increased presence of women reinforced the relationship between masculinity and agriculture. In the present study, however, it is not valid to argue that such an extreme reinforcement process was visible, even though a reproduction of "femininity" occurred. In a diverse workplace, it is important that managers understand the impact 
stereotypes have on members of the workforce (Flanagan, 2015). In order to reduce gender inequalities, it is therefore important to acknowledge the implications of management controls for doing gender, for the gendering of the workplace, and thus for the (re-)production of inequalities between the sexes. We need more research in this field.

\section{ACKNOWLEDGEMENTS}

The author wants to acknowledge the cooperation with Professor Åsa Cajander, Uppsala University, Dr. Hilde G. Corneliussen, researcher at Western Norway Research Institute, and Dr. Kari Dyb, senior researcher at Norwegian Center for E-health Research, for the development of interview questions and carrying out the interviews. The article is a development of a paper previously presented at the $2^{\text {nd }}$ International Conference on Gender Research, 11-13 April, 2019, Roma Tre University, Rome, Italy.

\section{REFERENCES}

Acker, J. (2006). Inequality Regimes Gender, Class, and Race in Organizations. Gender and Society, 20(4), 441-464.

Broadbent, J. (1998). The gendered nature of "accounting logic": Pointers to an accounting that encompass multiple values. Critical Perspectives on Accounting, 9, 267-297.

Brunila, K., \& Ylöstalo, H. (2015). Challenging gender inequalities in education and in working life - a mission impossible? Journal of Education and Work, 28(5), 443-460.

Brunsson, N. (1993). Ideas and actions: Justifications and hypocrisy as alternatives to control. Accounting, Organizations and Society, 18(6), 489-506.

Carmona, S. \& Ezzamel, M. (2016). Accounting and lived experience in the gendered workplace. Accounting, Organizations and Society, 49, 1-8.

Duszak, A. (2002). Us and Others: Social identities across languages, discourses and cultures. Amsterdam/Philadelphia: John Benjamin Publishing Company.

Erlingsdóttir, G., \& Lindholm, C. (2015). When patient empowerment encounters professional autonomy: The conflict and negotiation process of inscribing an eHealth service. Scandinavian Journal of Public Administration, 19(2), 27-48.

Flamholtz, E.G., Das, T.K., \& Tsui, A.S. (1985). Toward an integrative framework of organizational control. Accounting, Organizations and Society, 10(1), 35-50.

Flanagan, J. (2015). Gender and the workplace. The impact of stereotype threat on self-assessment of management skills of female business students. Advancing Women in Leadership. 35, 166-171.

Gherardi, S., \& Poggio, B. (2001). Creating and recreating gender order in organizations. Journal of World Business, 36(3), 245-259.

Giddens, A. (1984). The constitution of society: Outline of the theory of structuration. Cambridge: Polity Press.

Hernandez Bark, A.S., Escartin, J., Schuh, S.C., \& van Dick, R. (2016). Who leads more and why? A mediation model from gender to leadership role occupancy. Journal of Business Ethics, 139(3), 473-483.

Hines, R.D. (1992). Accounting: Filling the negative space. Accounting, Organizations and Society, 17(3/4), 313-341.

Hsieh, H.-F., \& Shannon, S.E. (2005). Three approaches to qualitative content analysis. Qualitative Health Research, 15(9), 1277-1288.

Inera. (2018a). Information about Inera's ehealth services at 1177 Vårdguiden. Retrieved from https://www.inera.se/tjanster/1177-vardguidens-e-tjanster/.

Inera. (2018b). Information about Inera. Retrieved from http://www.inera.se.

Kelan, E.K. (2007). Tools and toys: Communicating gendered positions towards technology. Information, Community and Society, 10(3), 358-383. 
Kelan, E.K. (2008). Emotions in a rational profession: The gendering of skills in ICT work. Gender, Work and Organization, 15(1), 49-71.

Leidner, R. (1991). Serving hamburgers and selling insurance: Gender, work and identity in interactive service jobs. Gender \& Society, 5(2), 154-77.

Liu, J.Y.-C., Chen, H.H.-G., Jiang, J.J., \& Klein, G. (2010). Task completion competency and project management performance: the influence of control and user contribution. International Journal of Project Management, 28(3), 220-227.

Martin, P.Y. (2006). Practicing gender at work: Further thoughts on reflexivity. Gender, Work and Organization. 13(3), 254-276.

McCarthy, M. M., Pickett, L. A., VanRyzin, J. W., \& Kight, K. E. (2015). Surprising origins of sex differences in the brain. Hormones and Behavior, 76, 3-10.

Mohanty, C.T. (2003). Feminism without borders. Deloconizing theory, practicing solidarity, Durham \& London, Duke University Press.

Moll, J., Rexhepi, H., \& Cajander, A. et al. (2018). Patients' experiences of accessing their EHRs: National patient survey in Sweden. Journal of Medical Internet Research, 20(11), e278.

Nentwich, J.C., \& Kelan, E.K. (2014). Towards a typology of 'doing gender': An analysis of empirical research and its challenges. Gender, Work and Organization, 21(2), 121-134.

Pilgeram, R. (2007). 'Ass-kicking' women: Doing and undoing gender in a US livestock auction. Gender, Work and Organization, 14(6), 572-595.

Rottenberg, C. (2014). The Rise of Neoliberal Feminism. Cultural Studies, 28(3), 418-437.

Scandurra, I., Holgersson, J., Lind, T., \& Myreteg G. (2013). Development of patient access to electronic health records as a step towards ubiquitous public eHealth. European Journal of ePractice, 2, 21 36.

Scott, W.R., Ruef, M., Mendel, P., \& Caronna, C. (2000). Institutional change and health care organizations: From professional dominance to managed care, Chicago: University of Chicago Press.

Selberg, R. (2012). Femininity at work: Gender, labour and changing relations of power in a Swedish hospital. Academic dissertation. Lund: Arkiv förlag \& Arkiv Academic Press.

Vårdguiden. (2018). The patient portal for eHealth services for citizens. Retrieved from https://www.1177.se

Wajcman, J. (2010). Feminist theories of technology. Cambridge Journal of Economics, 34, 134-152.

West, C., \& Zimmerman, D. H. (1987). Doing gender. Gender \& Society, 1(2), 125-151. 